\title{
Stability of fat globules in UHT milk during proteolysis by the AprX protease from Pseudomonas fluorescens and by plasmin
}

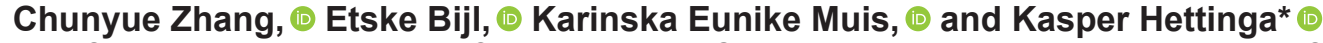 \\ Dairy Science and Technology, Food Quality and Design Group, Wageningen University and Research, PO Box 17, 6700 AA, Wageningen, \\ the Netherlands
}

\begin{abstract}
Fat separation is a limiting factor for the shelf life of UHT milk. It may be promoted by the proteolysis of fat surface-adsorbed proteins (FSAP) by proteases that remain active after UHT treatment. The aim of this research was to explore the relationship between the proteolysis of FSAP and fat destabilization. In this study, we developed a full-fat UHT milk-based model system and added either the major bacterial protease AprX from Pseudomonas fluorescens or the major native milk protease plasmin at high levels to induce fast destabilization of the milk fat globules. We monitored changes in physical properties and FSAP composition, and structural changes in fat globules, over $24 \mathrm{~h}$. Our results showed that AprX-induced sedimentation as a result of the flocculation of fat globules, and plasmin induced cream to float as a result of the coalescence of fat globules. This study confirmed that AprX and plasmin can both lead to fat destabilization in full-fat UHT milk, and it provides insights in the underlying mechanisms.
\end{abstract}

Key words: fat stability, UHT milk, proteolysis, AprX, plasmin

\section{INTRODUCTION}

The consumption of UHT-processed milk is increasing worldwide because of its long shelf life and the possibility of long-distance transport and storage at room temperature. However, its shelf life can be compromised by unwanted changes such as age gelation and sedimentation. For full-fat and semi-skimmed UHT milk, another possible detrimental change during storage is fat separation; the agglomeration of the fat globules with the formation of a floating fat layer or a fat-rich protein aggregate that is dense enough to sediment (Hardham et al., 2000; Chavan et al., 2011).

Received June 24, 2019.

Accepted September 12, 2019.

*Corresponding author: kasper.hettinga@wur.nl
Fat globules in UHT milk are heated and homogenized. Homogenization causes the native milk fat globules to mechanically disrupt into smaller particles, after which the natural milk fat globule membrane material is insufficient to cover the larger fat globule surface area. Hence, the surface of fat globules is covered and stabilized by adsorbed milk proteins, primarily caseins (Cano-Ruiz and Richter, 1997), which we will call "fat surface-adsorbed proteins" (FSAP). Fat separation during the shelf life of UHT milk has been commonly recognized to be caused by insufficient homogenization (Ramsey and Swartzel, 1984; Hardham et al., 2000). If fat globules do not achieve sufficient homogenization, a small number of fat globules will remain large and represent a significant volume of the total fat; these large globules can rise rapidly and cause a significant cream layer (Wilbey, 2011).

It is assumed that today, adequate homogenization is used in most commercial UHT production processes, so insufficient homogenization should not be a major issue. In UHT milk that has been adequately homogenized, proteolysis of FSAP could be the main cause of fat instability during storage. Such proteolysis of UHT milk may be caused by the residual activity of heat-stable proteases - mainly bacterial proteases, represented by $\mathrm{AprX}$, and native milk proteases, represented by the plasmin system. The AprX protease is a caseinolytic extracellular alkaline metalloprotease produced by Pseudomonas species (Zhang et al., 2019); with к-CN being most susceptible to its action, followed by $\beta$ - and $\alpha_{\mathrm{S} 1}-\mathrm{CN}$ (Recio et al., 2000; Zhang et al., 2018). Plasmin hydrolyzes in the order $\beta-\mathrm{CN}>\alpha_{\mathrm{S}^{-}} \mathrm{CN}>\alpha_{\mathrm{S}^{2}} \mathrm{CN}$, but barely hydrolyzes $\kappa$-CN (Rauh et al., 2014a; Zhang et al., 2018). In view of the differences in preferences of AprX and plasmin toward caseins, differences in AprX- and plasmin-induced protein destabilization of UHT milk (such as gelation and sedimentation) have been frequently reported (Rauh et al., 2014b; Matéos et al., 2015; Zhang et al., 2018). However, the influence of protease on fat destabilization has not been as well studied. It has been observed that in full-fat UHT milk, bacterial proteases lead to the formation of sediment or a custard-like gel (Visser, 1981; Harwalkar, 1992), 
whereas native proteases cause a creamy surface layer (Kohlmann et al., 1991; Hardham, 1998; Rauh et al., 2014b). However, the underlying mechanisms of how these 2 categories of proteases destabilize fat globules in UHT milk have not been unequivocally elucidated.

This study compared the differences between AprX and plasmin in hydrolyzing FSAP and the subsequent consequences for fat stability in UHT milk. To assess this, we added high levels of AprX or plasmin to fullfat UHT milk samples, to induce fast destabilization of milk fat globules without interference from nonenzymatic physicochemical changes.

\section{MATERIALS AND METHODS}

\section{Enzymatic Hydrolysis}

We obtained commercial full-fat UHT milk from FrieslandCampina (Venecolaan, Belgium). The type of processing used on the UHT milk was direct sterilization by steam infusion heat treatment according to additional information obtained from the manufacturer. The protein and fat content of the UHT milk was 3.6 and $3.5 \%$ (wt/vol), respectively, as analyzed by MilkoScan 134A/B (Foss Electric, Hillerød, Denmark). To have a low starting degree of hydrolysis, we used milk samples that were not older than 1 mo after manufacturing. To prevent spoilage during storage, we added $0.02 \%$ sodium azide as a preservative. We isolated the protease AprX from Pseudomonas fluorescens migula (DSM 50120) and purified it as described by Zhang et al. (2018). We purchased plasmin from bovine plasma (Roche 10602370001; Sigma-Aldrich, St. Louis, MO), which was suspended in $3.2 \mathrm{M}$ ammonium sulfate solution.

We determined the enzyme concentrations in a preliminary study. We found that the activity of $1 \mu \mathrm{L}$ of plasmin $/ \mathrm{mL}$ of milk, and the equivalent activity of AprX could induce obvious changes to fat stability in the model systems within $24 \mathrm{~h}$ of incubation at $37^{\circ} \mathrm{C}$. Samples were stored at $37^{\circ} \mathrm{C}$ to accelerate destabilization. Our previous study has shown that storage at $37^{\circ} \mathrm{C}$ will not change the hydrolysis patterns of milk proteins by AprX and plasmin - only hydrolysis rate (Zhang et al., 2018). In the main experiment, we weighed crude AprX extract into full-fat UHT milk samples at a concentration of $84 \mu \mathrm{g} / \mathrm{mL}$, whose activity matched $1 \mu \mathrm{L}$ of plasmin $/ \mathrm{mL}$ of milk. We determined the activity of plasmin and AprX using the azocasein assay as described by Dufour et al. (2008). Samples were collected at 4 -h intervals over $24 \mathrm{~h}$ of incubation at $37^{\circ} \mathrm{C}$, after which the samples were used for physical stability measurement and FSAP analysis.

\section{Characterization of Physical Stability During Proteolysis}

Measuring Fat Content in Different Layers. The samples for fat content measurement were placed in a standing position without disturbance. After incubation, a pipette tip was slowly inserted along the inner wall of the tube until reaching the bottom without stirring the milk.

Then we collected the same volume from the bottom, middle, and top layers successively from this vial. Lipid extraction from full-fat UHT milk samples was optimized based on the methods of Lu et al. (2018), using a mixture of hexane and isopropanol $(3: 2, \mathrm{vol} / \mathrm{vol})$. The milk sample was mixed with the organic solvent mixture at a ratio of 1:5 (vol/vol) in a capped Eppendorf tube. The tubes were incubated at $60^{\circ} \mathrm{C}$ for $15 \mathrm{~min}$ with occasional gentle shaking to aid lipid extraction (Baümler et al., 2010). Then, the upper organic phase was collected in a weighed tube, dried under a stream of nitrogen, and weighed again, with the increase in weight used to calculate fat content.

Stability Analysis by LUMiFuge. We examined the physical stability of the hydrolyzed samples using LUMiFuge (LUM GmbH, Berlin, Germany), an optical stability analyzer that accelerates physical destabilization by centrifugal force and exposes sample cells to near-infrared light while measuring transmission continuously during centrifugation. High concentrations of particles yield low transmission profiles, and vice versa. Before analysis but after incubation, we diluted the samples 10 times with simulated milk ultrafiltrate (SMUF; pH 6.8) to reduce the turbidity of full-fat UHT milk and facilitate optical measurement. The SMUF was prepared according to Jenness and Koops (1962)

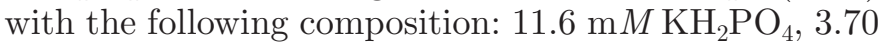
$\mathrm{m} M \mathrm{C}_{6} \mathrm{H}_{5} \mathrm{~K}_{3} \mathrm{O}_{7} \cdot \mathrm{H}_{2} \mathrm{O}, 6.09 \mathrm{~m} M \mathrm{C}_{6} \mathrm{H}_{5} \mathrm{Na}_{3} \mathrm{O}_{7} \cdot 2 \mathrm{H}_{2} \mathrm{O}, 1.03$ $\mathrm{m} M \mathrm{~K}_{2} \mathrm{SO}_{4}, 8.05 \mathrm{~m} M \mathrm{KCl}, 8.97 \mathrm{~m} M \mathrm{CaCl}_{2} \cdot 2 \mathrm{H}_{2} \mathrm{O}$, and $3.20 \mathrm{mM} \mathrm{MgCl} 2 \cdot 6 \mathrm{H}_{2} \mathrm{O}$. The sample was then agitated by gently shaking from side to side, after which a $400-\mu \mathrm{L}$ sample was inserted into LUMiFuge sample cells [LUM $2 \mathrm{~mm}$, PC, rectangular synthetic cell (110-131xx)]. We carried out the LUMiFuge measurements at 2,300 $\times g$ for $43 \mathrm{~min}$ at room temperature, and measured transmission for 255 cycles of $10 \mathrm{~s}$ at a near-infrared wavelength of $865 \mathrm{~nm}$. These parameters were set according to Sunds (2016).

To quantify the emulsion stability of the samples, we used the integrated transmission percentage against time, referred to after this as the "instability index." We automatically calculated the instability index using the LUMiFuge software SEPView 6.3. Lower instability index values indicate better emulsion stability. 
Size Distribution of Milk Particles. We performed a particle size distribution analysis using laser light diffraction (Mastersizer 3000; Malvern Instruments Ltd., Malvern, UK). Samples diluted 50 times with MilliQ water were injected directly into the dispersion cell under agitation at $1,500 \mathrm{rpm}$. We avoided a higher stirring intensity to prevent disintegration of aggregates. Droplet size was calculated with a refractive index of 1.45 and 1.33 for the droplet and continuous phase (MilliQ water), respectively. The particle absorption index was set at 0.002 .

Viscosity. We measured the viscosity of the samples in a stress-controlled rheometer (MCR 302; Anton Paar, Graz, Austria), using a double-gap concentric cylinder geometry (MCR 72; Anton Paar). We used a solvent trap to prevent evaporation. The samples were stabilized for $2 \mathrm{~min}$. Then, we monitored viscosity by exponentially increasing the shear rate from 0.01 to 500 $\mathrm{s}^{-1}$. Measurements were performed at $20^{\circ} \mathrm{C}$.

FSAP Isolation. The method was optimized based upon previously described methods by McCrae et al. (1994); McPherson et al. (1984) and Lu et al. (2016). The FSAP isolation method had 2 parts: cream separating and washing. Cream was separated from full-fat UHT milk samples by ultracentrifugation at $60,000 \times$ $g$ for $1 \mathrm{~h}$ at $20^{\circ} \mathrm{C}$ using an L60 Beckman ultracentrifuge (Beckman, Fullerton, CA; 70 Ti rotor). To aid the separation of fat droplets from milk serum, 0.6 M sucrose was incorporated before centrifugation as density-increasing agent. Pre-experiments showed that after ultracentrifugation with the aid of sucrose, the cream layer of UHT milk samples was as thick as that of raw milk, indicating that most milk fat ended up in the cream layer. Immediately after ultracentrifugation, the samples were immersed into an ice bath for $15 \mathrm{~min}$ to solidify the cream layer. The cream was then collected in a new tube and washed. To wash away the proteins that were loosely attached or entrapped in the cream layer, we washed the collected cream in 3 steps: (1) submersion of the cream layer $(1: 10, \mathrm{wt} / \mathrm{vol})$ in SMUF with added sucrose $(35 \% \mathrm{wt} / \mathrm{vol})$; (2) centrifugation at $21,000 \times g$ for $10 \mathrm{~min}$ at $10^{\circ} \mathrm{C}$; (3) discarding the washing solution, and collection of the cream layer. After repeating the 3 -step washing procedure 3 times, we weighed the washed cream fraction and analyzed the FSAP with reversed-phase HPLC and SDS-PAGE.

\section{Characterization of Protein Profile in FSAP During Proteolysis}

Reversed-Phase HPLC. We determined the protein composition by reversed-phase HPLC (UltiMate 3000; Thermo Scientific, Waltham, MA) equipped with an Aeris Widepore $3.6 \mu \mathrm{m}$ XB-C18 column $(250 \times 4.6$ mm; Phenomenex, Utrecht, the Netherlands), according to the method described by Zhang et al. (2018). We used protein standards $\left(\beta-\mathrm{CN}, \alpha_{\mathrm{S}_{1}}-\mathrm{CN}, \alpha_{\mathrm{S} 2}-\mathrm{CN}\right.$, $\kappa-\mathrm{CN}, \alpha-\mathrm{LA}$, and $\beta$-LG; all with purities of $70-98 \%$; Sigma-Aldrich) to validate the elution times of milk proteins. We analyzed the resulting chromatograms using Chromeleon 7.1.2 software. The changes in $\alpha_{S_{2}-}$ CN could not be quantitatively described because of the coelution of peaks of $\alpha_{S_{2}}$ CN with breakdown products of protein hydrolysis, as explained by Rauh et al. (2014b).

$S D S-P A G E$. We performed SDS-PAGE under reducing conditions to complement the reversed-phase HPLC results. The sample buffer, reducing agent, gels, running buffer and antioxidant agent were all purchased from Invitrogen (Carlsbad, CA). The washed cream was diluted 30 times with SMUF; $5 \mu \mathrm{L}$ of diluted cream was mixed with $5 \mu \mathrm{L}$ of $4 \times$ concentrated $\mathrm{Nu}$ PAGE LDS sample buffer, $2 \mu \mathrm{L}$ of $10 \times$ concentrated NuPAGE sample reducing agent, and $10 \mu \mathrm{L}$ of MilliQ water. Then, the mixture was centrifuged at $425 \times g$ for $1 \mathrm{~min}$ and heated at $70^{\circ} \mathrm{C}$ in a heating block (Labtherm Graphit, Liebisch, Germany) for 10 min. Samples were loaded onto NuPAGE Novex 12\% Bis-Tris gels. We applied the BlueRay Prestained Protein Marker 10 to 180 kDa (Jena, Germany) as a reference. We used NuPAGE MES buffer with $0.5 \mathrm{~mL}$ of NuPAGE antioxidant for running the gels. Electrophoresis was performed using an XCell SureLock unit (Invitrogen, Paisley, UK) at constant voltage $(120 \mathrm{~V})$. The gels were stained with Coomassie.

\section{Characterization of Microstructure of Fat Globules}

Confocal Laser Scanning Microscopy. We observed the distribution of lipids and protein and their aggregation with a Zeiss LSM 510-META 18 confocal laser scanning microscope (CLSM; Zeiss, Oberkochen, Germany). The stock solutions of protein-specific stain rhodamine B (Sigma-Aldrich; $10 \mathrm{mg} / \mathrm{mL}$ ) and lipidspecific stain Bodipy 505/515 (Invitrogen Molecular Probes, Carlsbad, CA; $5 \mathrm{mg} / \mathrm{mL}$ in $70 \%$ ethanol) were mixed and diluted in SMUF to a final concentration of $1 \mathrm{mg} / \mathrm{mL}$. We added $1 \mu \mathrm{L}$ of mixed stain to $99 \mu \mathrm{L}$ milk sample, then vortexed it and dropwise transferred it to a cavity slide.

The CLSM was connected to an inverted microscope (Axiovert 200M, Carl Zeiss, Göttingen Germany) with differential interference contrast. The Bodipy 505/515 stain was excited with an Argon laser (488 nm), and emission wavelengths between $505 \mathrm{~nm}$ and $530 \mathrm{~nm}$ were detected. We used an He-Ne laser operated at an excitation wavelength of $543 \mathrm{~nm}$ and emission wavelengths of $560 \mathrm{~nm}$ and higher to detect rhodamine B. All images were acquired using a Plan-Apochromat $63 \times$ oil 
immersion objective (1.4 numerical aperture) with a resolution of $512 \times 512$ pixels, and the pinhole of the microscope was set to $84 \mu \mathrm{m}$. The samples stained with both dyes were analyzed by multi-channel tracking to enable the visibility of the dyes.

Cryostation Scanning Electron Microscope. To analyze the morphological changes of fat globules in UHT milk after enzymatic hydrolysis, we took cryogenic scanning electron microscope (Cryo-SEM) images at distinct times after incubation with proteases. We transferred a $10-\mu \mathrm{L}$ milk sample to a copper hollow rivet and quickly plunged it into liquid nitrogen for snap-freezing. We transferred the sample holder to a cryopreparation system (MED 020/VCT 100; Leica, Vienna, Austria) in which the samples were fractured and freeze-dried to remove water vapor contamination. Then, the samples were sputter coated with a layer of $15 \mathrm{~nm}$ tungsten. Samples were cryo-shielded transferred into the field-emission scanning microscope (FEI Magellan 400; FEI, Eindhoven, the Netherlands) equipped with a Leica cold stage for Cryo-SEM. We performed the analysis at a working distance of $4.2 \mathrm{~mm}$, with secondary electron detection at an acceleration voltage of $2 \mathrm{kV}$. The particle size distribution was analyzed by Image J software (1.51f, National Institutes of Health, Bethesda, MD).

\section{Statistical Analysis}

All measurements were performed in biological triplicates, and results are expressed as means and standard deviations. We analyzed data using 1-way repeatedmeasures ANOVA and Tukey as a post hoc test in SPSS version 24 (SPSS Inc., Chicago, IL). Statistical significance was set as $P<0.05$.

\section{RESULTS AND DISCUSSION}

\section{Change of Physical Stability}

Change of Fat Content in Different Layers. The fat redistribution was monitored by measuring the fat content in the top, middle, and bottom layers of the sample tubes. As shown in Figure 1a, in the samples incubated with AprX the fat in the top layer started to decrease from $12 \mathrm{~h}$ onward $(P<0.05)$, whereas the fat content in the middle and bottom layers increased from $12 \mathrm{~h}$ and $16 \mathrm{~h}(P<0.001)$, respectively, indicating that fat started to sediment. In contrast, in plasminhydrolyzed samples the fat content in the bottom layer decreased after $0 \mathrm{~h}(P<0.05)$, along with an increase of fat content in the top layer $(P<0.05$, Figure $1 b)$, indicating that fat globules had floated to the surface. Similar plasmin-induced redistribution of fat in different layers of UHT milk during storage has been reported by Malmgren et al. (2017), who observed an increase in fat content in the top layers and a reduction in the lower layers.

Stability Test by LUMiFuge. Owing to high turbidity, fat separation was difficult to judge visually in full-fat UHT samples until the sample clarified. Therefore, we used LUMiFuge to aid in analyzing the particle

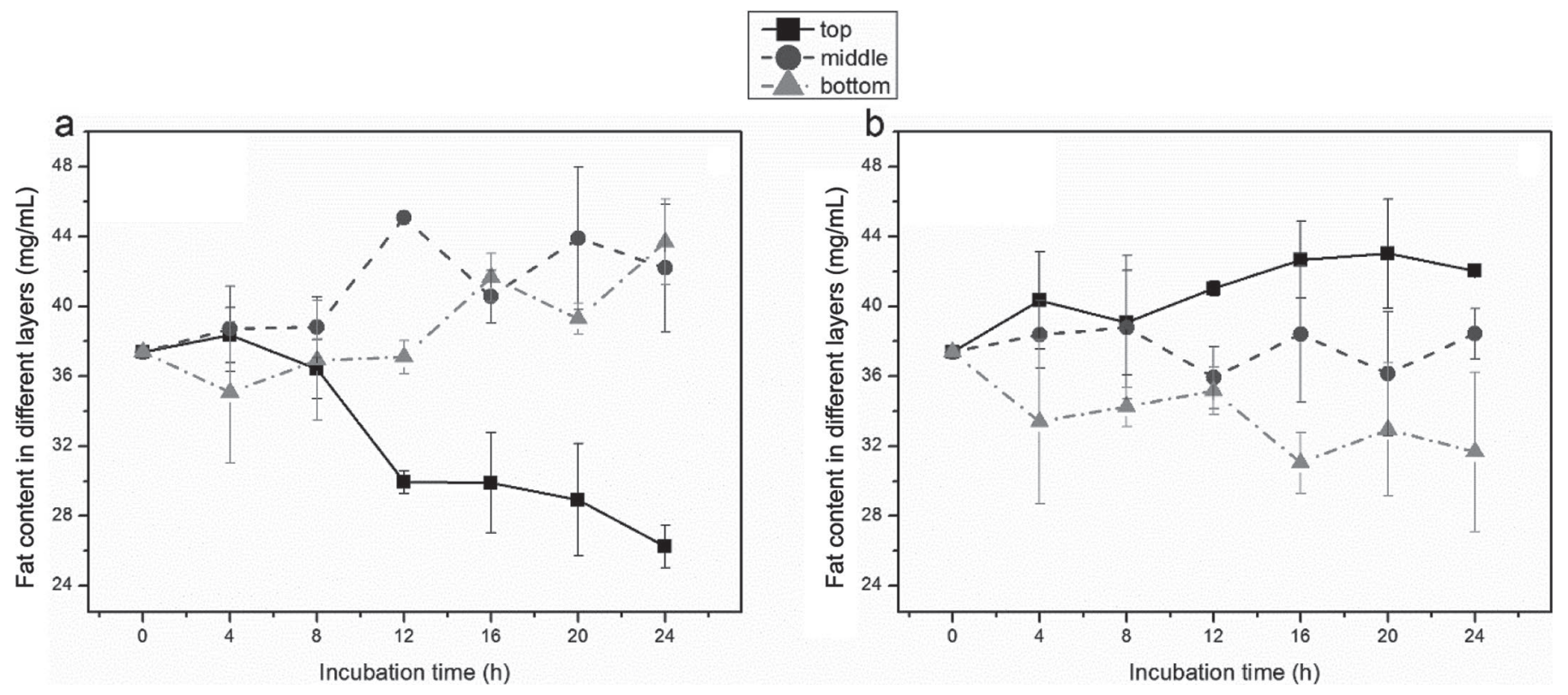

Figure 1. Fat content in the top, middle, and bottom layers of full-fat UHT milk samples incubated with (a) AprX protease and (b) plasmin. Data are presented as mean $\pm \mathrm{SD}$ of triplicates. 


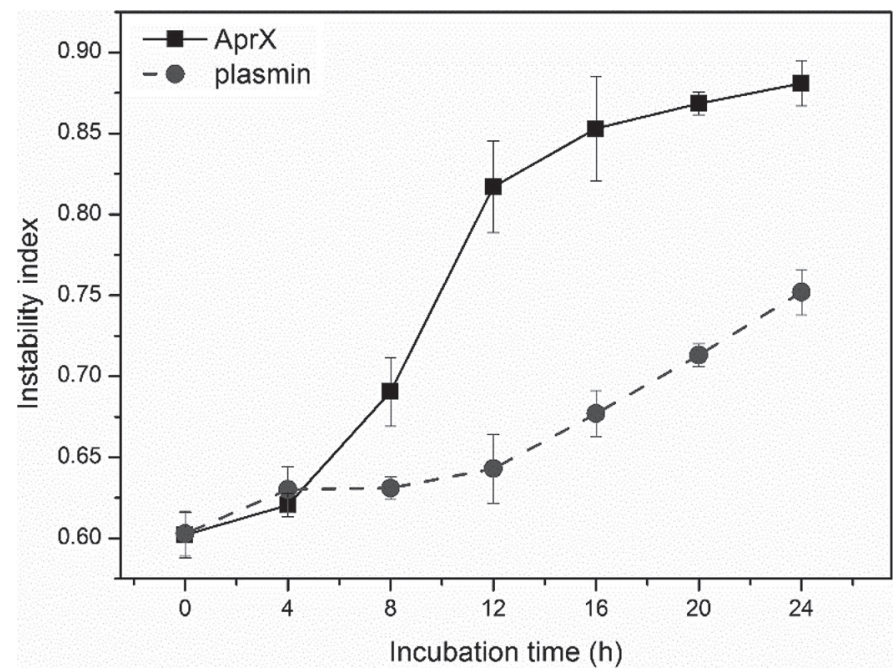

Figure 2. Instability index obtained by LUMiFuge of full-fat UHT milk samples incubated with AprX protease and plasmin. All samples were diluted 10 -fold to facilitate optical measurement. Data are presented as mean $\pm \mathrm{SD}$ of triplicates.

migration by calculating the instability index according to the transmission profiles under centrifugal forces. As shown in Figure 2, the instability index increased during incubation in both AprX- and plasmin-containing samples, indicating that sample destabilization happened in both systems. For the samples incubated with AprX, the instability index rapidly increased between 4 and $12 \mathrm{~h}(P<0.001)$ : creaming gradually changed to sedimentation, as shown by the shape of the transmission profiles (Supplemental Figure S1; https://doi.org/ 10.3168/jds.2019-17150). The instability index increased more slowly in the plasmin-containing samples than in

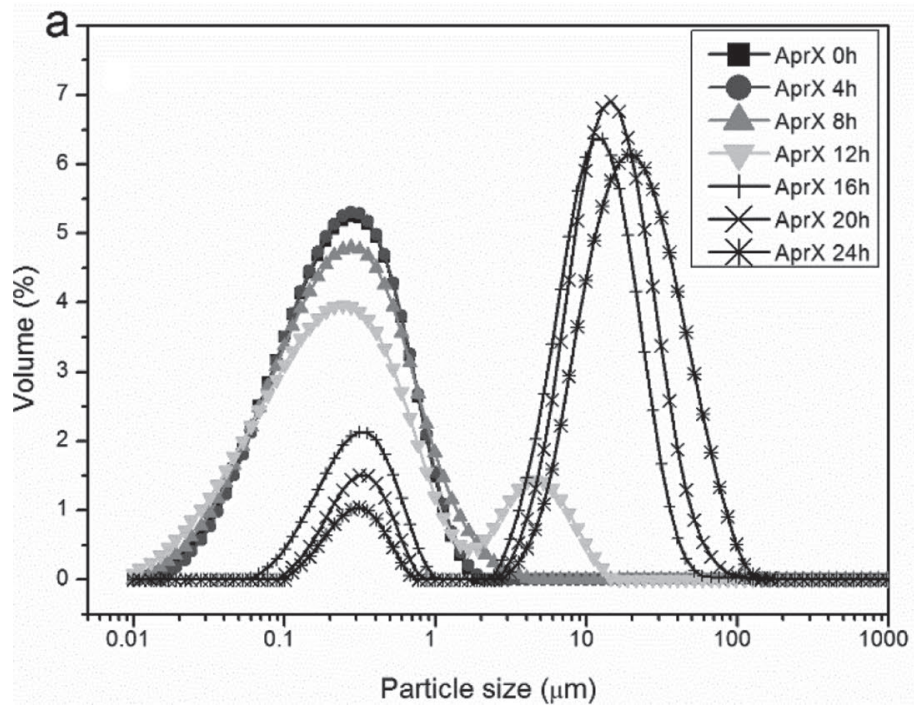

the AprX-containing samples, with more creaming and less sedimentation formed, as inferred from the transmission profiles.

Size Distributions. We monitored the changes in size distribution of all colloidal particles in full-fat UHT milk - which included casein micelles, fat globules, and the agglomerates that may form - during hydrolysis by AprX and plasmin (Figure 3). The blank full-fat UHT milk at $0 \mathrm{~h}$ of incubation had a pseudo-monomodal size distribution centered at approximately $0.2 \mu \mathrm{m}$, which was 2 overlapping distributions: the casein micelles were smaller than the average and the fat globules were larger. A similar pseudo-monomodal size distribution of full-fat UHT milk was reported by Matéos et al. (2015).

For the UHT milk containing AprX (Figure 3a), the size distribution started to broaden at $8 \mathrm{~h}$. A new peak appeared in the micron size range at $12 \mathrm{~h}$ and shifted to over $10 \mu \mathrm{m}$ in the subsequent incubation times. Meanwhile, the peak corresponding to regular particles in the sample before incubation gradually diminished, indicating that the small particles were incorporated in the larger aggregates. This observation was in agreement with earlier findings, where large aggregates ranging from 2 to $100 \mu \mathrm{m}$ were reported in full-fat UHT milk (Matéos et al., 2015). However, in skim UHT milk samples incubated with AprX, these aggregates have also been observed (Baglinière et al., 2013; Zhang et al., 2018), indicating that the underlying mechanism for aggregate formation could be similar. It can also be speculated that fat is entrapped in the formed protein aggregate, similar to cheese production.

Compared with the AprX-containing samples, the size distribution changed to a lesser extent in the

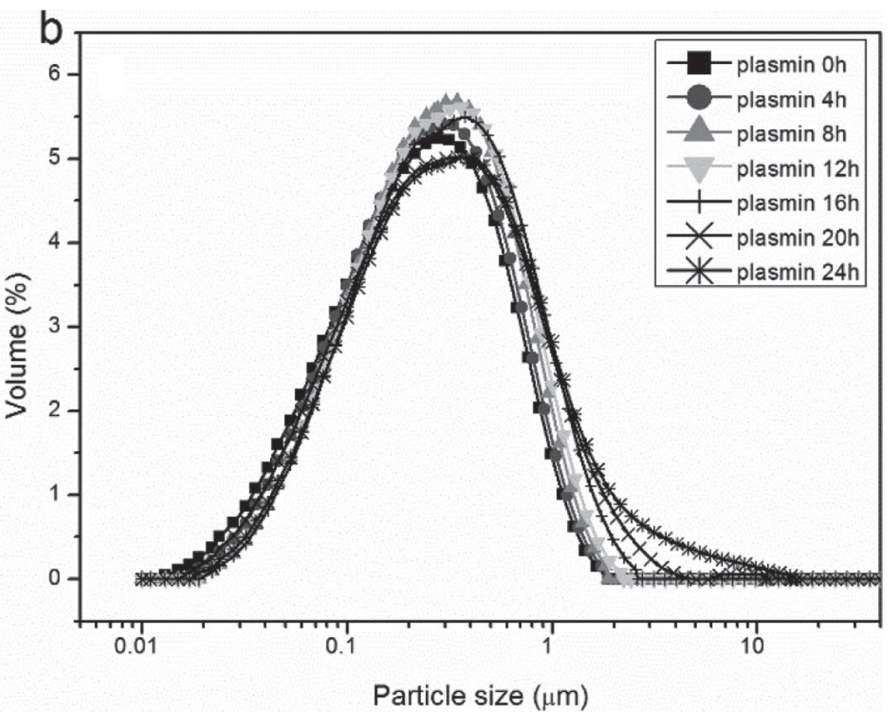

Figure 3. Volume-based particle size distribution in blank full-fat UHT milk samples incubated with (a) AprX protease and (b) plasmin. 
plasmin-containing samples. No new peaks appeared, but the average size slightly increased $(P<0.05)$, and a population of particles with a size larger than $2 \mu \mathrm{m}$ arose, indicating that larger particles were formed during hydrolysis by plasmin. Similar changes in size distribution have also been found in semi-skim UHT milk $(1.5 \%$ fat, wt/vol) with residual plasmin activity during storage (Rauh et al., 2014b). But the plasmin-induced changes in particle size distribution in the skim UHT milk (0.07\% fat, wt/vol) was slightly different: the peak corresponding to native casein micelles shifted instead of broadening to a larger size (Zhang et al., 2018), which may have been because skim milk contains only casein micelles, making the peak sharper, whereas in non-skim homogenized milk, the peaks of casein micelles and fat globules overlap.

Viscosity. The flow behavior of milk as determined by a rheometer is closely related to consumers' perception of viscosity. Figure 4 displays the apparent viscosity curves for both AprX- and plasmin-hydrolyzed samples. The viscosity of samples with AprX and plasmin both showed shear thinning behavior, and viscosity increased with incubation time.

In AprX-containing samples, after incubation for $8 \mathrm{~h}$, the viscosity increased sharply, to more than $10 \mathrm{mPa} \cdot \mathrm{s}$ (at $20^{\circ} \mathrm{C}$; Figure $4 \mathrm{a}$ ), which is generally regarded as a manifestation of age gelation in UHT milk (Datta and Deeth, 2001; Deeth and Lewis, 2016). This coincided with the time that the sedimentation started (Figure 1) and large agglomerates were formed (Figure 3 ). Therefore, we can conclude that a gel network formed after $8 \mathrm{~h}$. In comparison, the viscosity in plasmin-containing samples rose steadily, indicating that the changes in the microstructure were gradual and progressive. In our

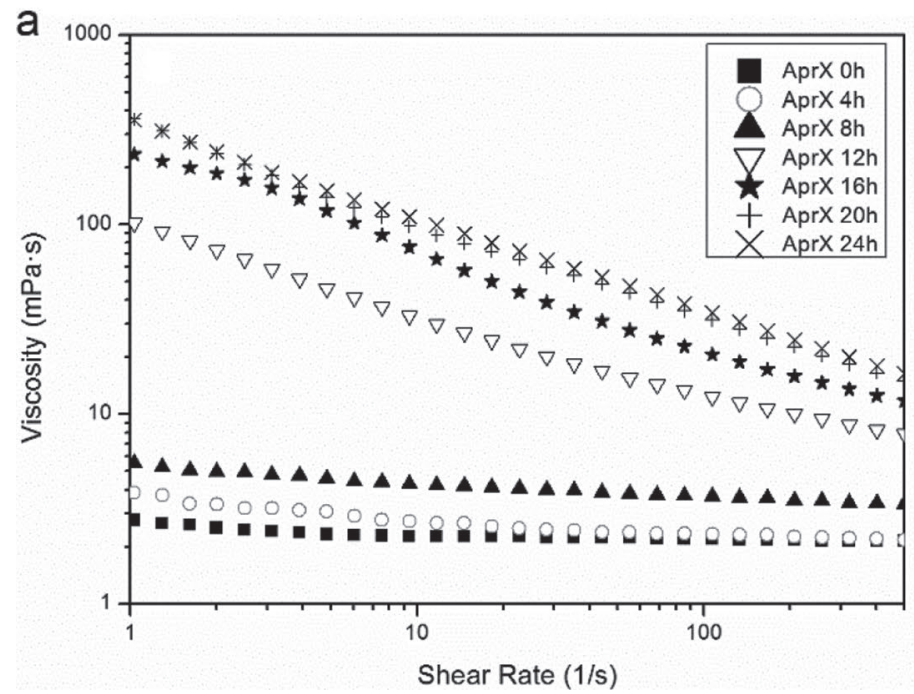

study, none of the plasmin-containing samples reached a viscosity higher than $10 \mathrm{mPa} \cdot \mathrm{s}$ (Figure 4b). But fat floating was detected (Figure 1), showing that creaming happened earlier than gelation in our plasmincontaining UHT milk.

Comparing these 2 systems, AprX induced a greater increase in viscosity and a less pronounced shear thinning behavior than plasmin, showing that AprX induced the formation of stronger network structures than plasmin.

\section{Change of FSAP Content and Composition}

Change of FSAP Content. To explain how fat stability may be influenced by the hydrolysis of FSAP, we further studied the samples with AprX or plasmin for their FSAP content and composition. Because the same ratio of milk fat ended up in the cream layer after ultracentrifugation, we attributed the differences in the weight of the cream layer per unit milk mainly to the different content of hydrated FSAP. As shown in Figure 5, in the milk with AprX, the weight of cream started to increase rapidly after $8 \mathrm{~h}(P<0.001)$ and remained constant after $20 \mathrm{~h}$. In milk with plasmin, the weight of the cream layer decreased in the first 12 $\mathrm{h}(P<0.005)$ and remained constant afterward. We found trends similar to those for weight of cream in both systems when FSAP concentration in the washed cream was quantified using HPLC and expressed as the total HPLC peak area (Figure 5). Both measurements showed that more protein was trapped in the cream layer along with the hydrolysis by AprX, whereas part of the FSAP seemed to be released to the serum when hydrolyzed by plasmin.

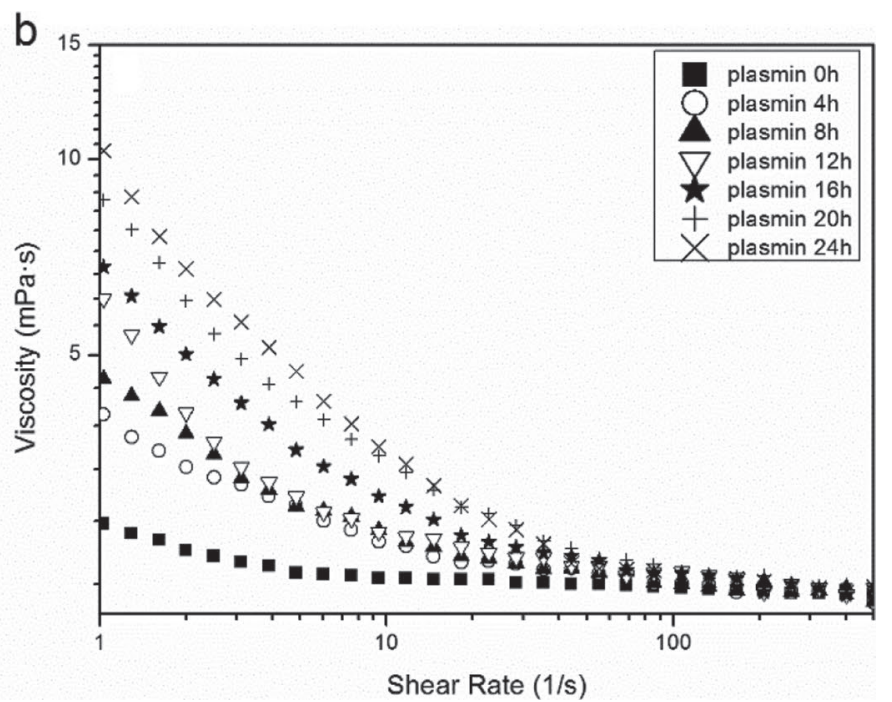

Figure 4. Viscosity of full-fat UHT milk samples incubated with (a) AprX protease and (b) plasmin as a function of shear rate. 

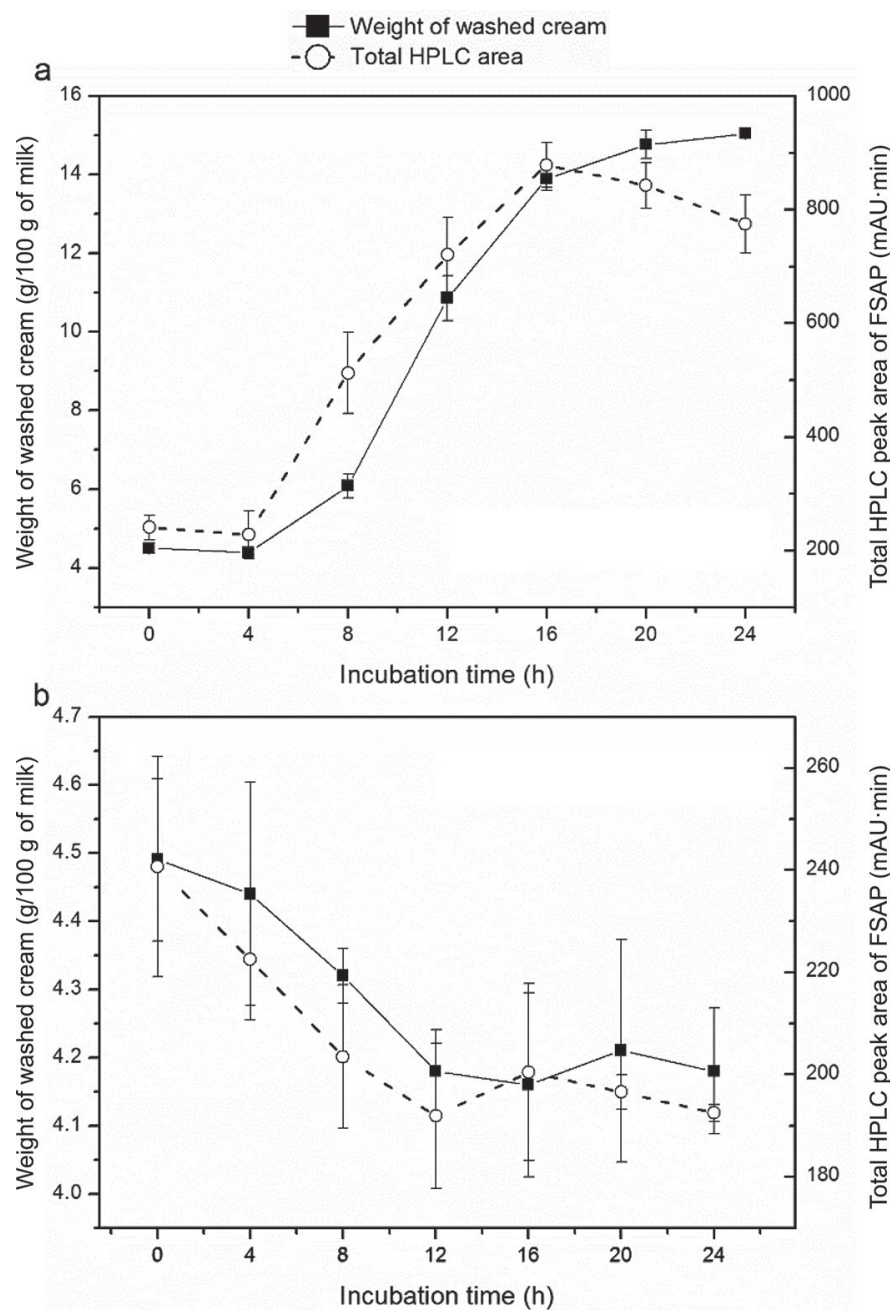

Figure 5. Weight of washed cream and total HPLC peak area of fat surface-adsorbed proteins (FSAP) after integration of UV absorbance at $214 \mathrm{~nm}$ of full-fat milk samples incubated with (a) AprX protease and (b) plasmin. Data are presented as mean \pm SD of triplicates.

Change of FSAP Composition. We studied the changes in FSAP composition during incubation of the full-fat UHT milk samples with AprX or plasmin using reversed-phase HPLC and SDS-PAGE (Figure 6). In AprX-hydrolyzed samples, $\alpha_{\mathrm{S}_{1}}$ and $\beta$-CN remained constant in the first $4 \mathrm{~h}$, but started to increase sharply between 4 and $16 \mathrm{~h}(P<0.001)$, after which they declined slightly $(P<0.05$; Figure 6a). Meanwhile, almost all the $\kappa$-CN was rapidly hydrolyzed within the first 4 $\mathrm{h}(P<0.001)$. In addition, the peak area of whey proteins increased gradually upon hydrolysis $(P<0.001)$. On SDS-PAGE, the band corresponding to $\kappa-\mathrm{CN}$ diminished rapidly (Figure 6c). It is known that AprX preferably cleaves the peptide bond Phe105-Met106

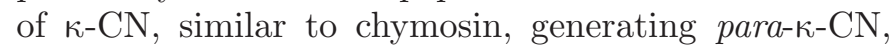
which remains in casein micelles and glycomacropeptide that goes into serum (Zhang et al., 2019). However, no band of para-k-CN (located at approximately 15 $\mathrm{kDa}$ ) was visible on the gel, possibly because AprX can further cleave the para- $\kappa-\mathrm{CN}$ molecule during storage (Matéos et al., 2015). The numerous bands exhibited after $12 \mathrm{~h}$ might correspond to the breakdown products of $\alpha-$ and $\beta-\mathrm{CN}$.

After the incubation with plasmin, $\alpha_{\mathrm{S1}^{-}}$and $\beta-\mathrm{CN}$ in FSAP significantly decreased $(P<0.005)$, but $\kappa-\mathrm{CN}$ and whey proteins remained constant. Although the decrease in $\alpha_{S^{-}}$and $\beta$-CN were not obvious from the gel (Figure 6d), some new bands could be observed after incubation for $8 \mathrm{~h}$. The bands located at approximately 25,15 , and $12 \mathrm{kDa}$ may have corresponded to the major breakdown products of $\beta-\mathrm{CN}$ by plasmin, which are f29-209 $\left(\gamma_{1}-\mathrm{CN}\right)$, f69-209 $\left(\gamma_{4}-\mathrm{CN}\right)$, f106-209 $\left(\gamma_{2}-\mathrm{CN}\right)$, and f108-209 ( $\gamma 3-\mathrm{CN}$; Figure 6d; Petrella et al., 2015).

\section{Microstructure of Fat Globules with Hydrolyzed FSAP}

We visualized the microstructure of the blank and full-fat UHT milk with AprX or plasmin using confocal laser scanning microscopy after incubation for 16 $\mathrm{h}$ (Figure 7). We selected these samples because the FSAP fraction in both milk samples seemed to not change further from this time onward (Figure 5, 6). Protein and lipids were stained red and green, respectively. In the blank full-fat UHT milk, both the casein micelles (Figure 7a) and the fat globules (Figure 7b) had uniform sizes and were homogeneously distributed. No aggregation was observed (Figure $7 \mathrm{a}-\mathrm{c}$ ).

In the AprX-hydrolyzed samples, in contrast, we observed a remarkably different state of fat and protein. We found a dense gel network in the red protein channel (Figure 7d), and the fat globules, which are shown as green spots, remained as individual droplets (Figure 7e) embedded in the protein gel network (Figure 7f). Compared with traditional dairy products, the AprXinduced network structure was more compact than the open gel of full-fat yogurt, where colloidal calcium phosphate is dissolved and the $\kappa-\mathrm{CN}$ brush collapses (Torres et al., 2012). However, the network was similar to chymosin-induced milk gel (Ong et al., 2011), which agreed with the results discussed in Size Distributions, above.

In plasmin-hydrolyzed samples, we observed some red circles in the protein channel (Figure $7 \mathrm{~g}$ ) and large green spots in the lipid channel (Figure 7h), as indicated by the white arrows. The green spots, corresponding to fat globules, were larger than those in the blank and AprX-hydrolyzed samples, in line with the increase in particle size (see Size Distributions; Figure 3b) and indicating fat coalescence in these samples. After combining the channels, we found that the coalesced fat globules 
were covered by a thin continuous layer of proteins (Figure $7 \mathrm{i}$ ). The increase or decrease of these coalesced fat globules is determined by the protein-to-fat ratio. In our case, the relative amount of protein associated with the fat globules decreased upon hydrolysis by plasmin (Figure 5,6). As a result, the average density of the fat globules would drop and the density of fluid would increase. Therefore, according to Stokes' law, the coalesced fat globules would float to the surface, which was in agreement with our findings in Figure 1b.

We took Cryo-SEM images to investigate the morphologic changes of the fat globules in UHT milk, and to use as examples to further strengthen our theory. Fat globules could be easily distinguished from casein micelles, because casein micelles were smaller than fat globules and present as uniform, imperfectly spherical particles. The size of the casein micelles in UHT milk ranged from 50 to $200 \mathrm{~nm}$, with an average diameter of about $100 \mathrm{~nm}$ (Supplemental Figure S2; https://doi .org/10.3168/jds.2019-17150). Kamigaki et al. (2018) reported a similar distribution of casein micelle sizes based on observation of casein micelles in raw milk, with an average diameter of about $140 \mathrm{~nm}$. The smaller average diameter we observed in our samples may be

\section{a}
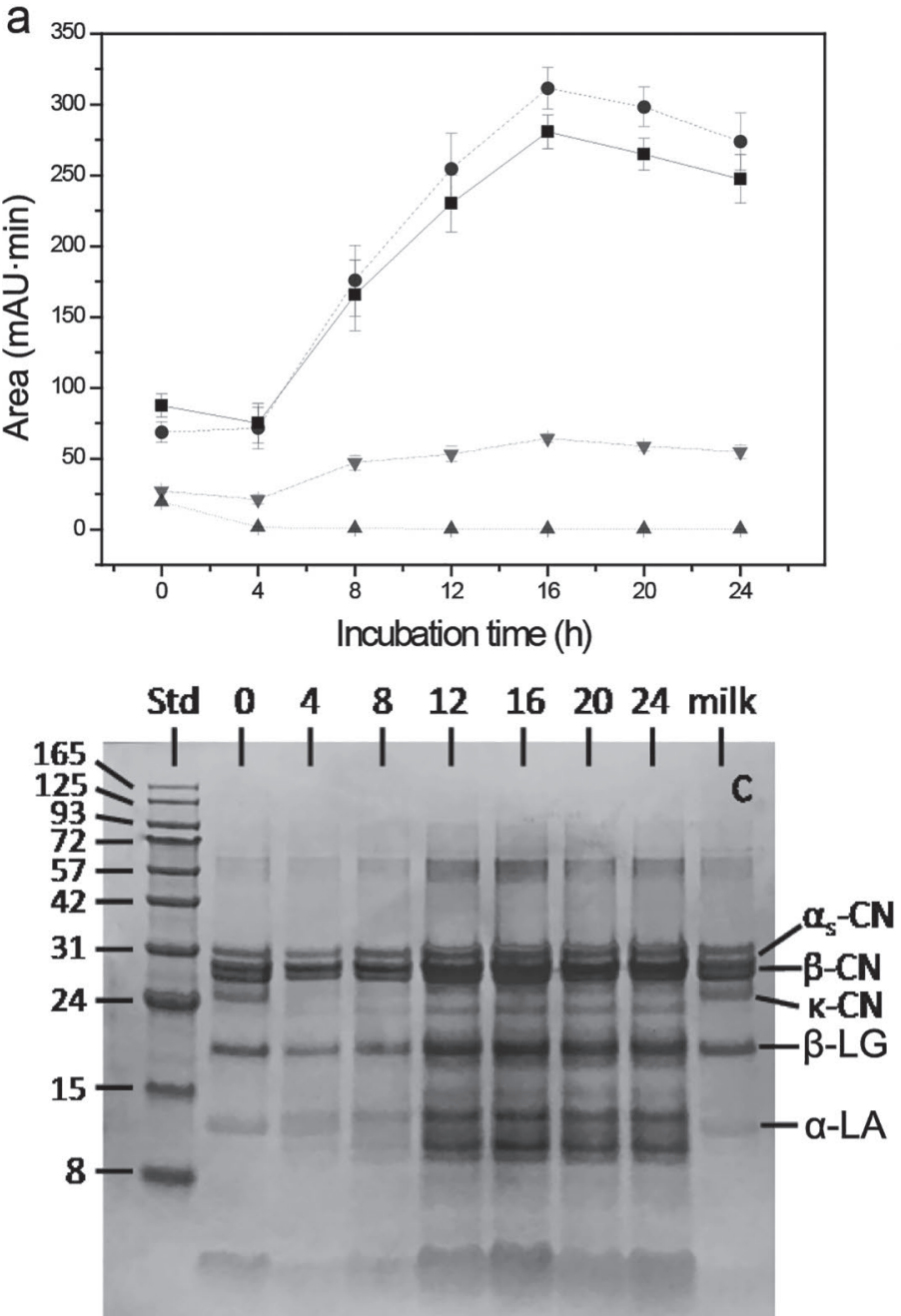

\section{$-\beta-\mathrm{CN}$}

$\alpha_{s 1}-\mathrm{CN}$

A... $\mathrm{k}-\mathrm{CN}$

$\checkmark$ whey proteins

\section{$\mathrm{b}$}
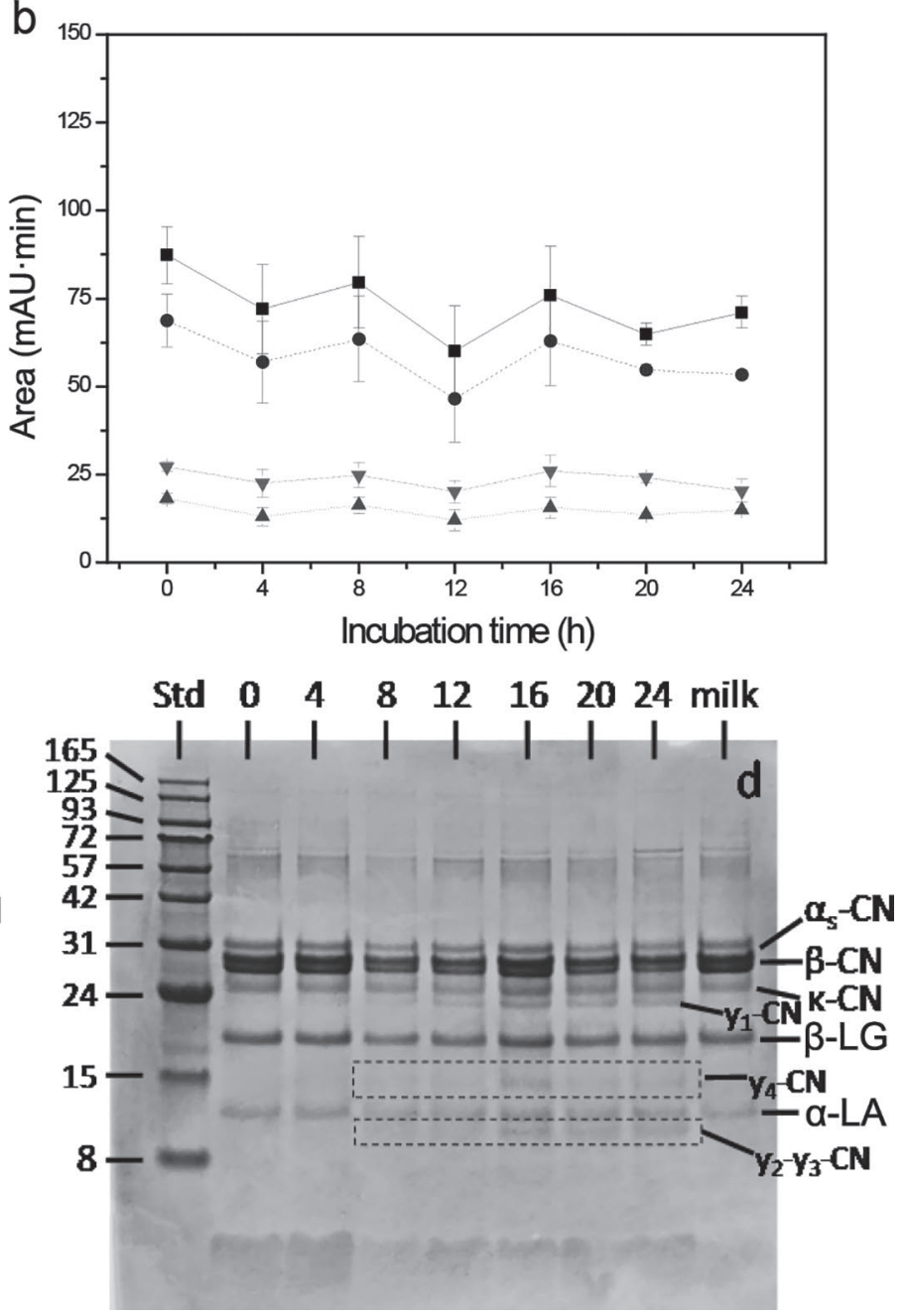

Figure 6. Changes of $\alpha_{\mathrm{S}_{1}} \mathrm{CN}, \beta-\mathrm{CN}, \kappa-\mathrm{CN}$, and total whey proteins in the fat surface adsorbed protein (FSAP) fraction in full-fat UHT milk samples incubated with (a) AprX protease and (b) plasmin, expressed as the total peak area of UV absorption at $214 \mathrm{~nm}$ using reversedphase HPLC. Data are presented as mean \pm SD of triplicates. The SDS-PAGE patterns of full-fat UHT milk samples incubated with (c) AprX protease and (d) plasmin; numbers above the gel indicate the incubation time (hours) with protease. $\alpha_{S^{-}} \mathrm{CN}=\alpha_{\mathrm{S} 1}+\alpha_{\mathrm{S} 2^{-}}$casein; milk $=$full-fat UHT milk without the addition of protease; Std = molecular mass standards. 


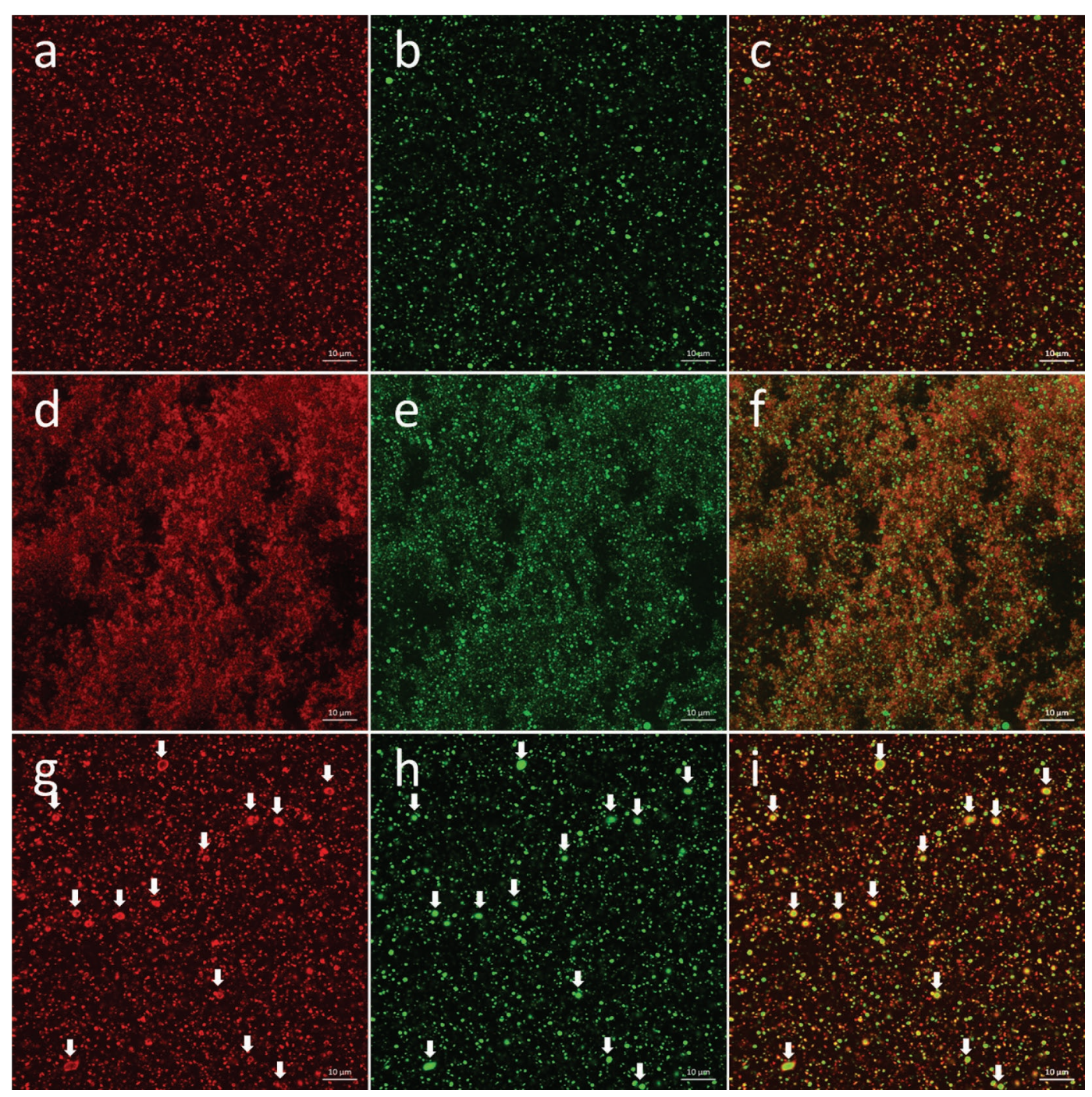

Figure 7. Confocal micrographs showing the microstructure of $(\mathrm{a}-\mathrm{c})$ blank full-fat UHT milk, (d-f) full-fat UHT milk samples incubated with AprX protease or $(\mathrm{g}-\mathrm{i})$ plasmin at $37^{\circ} \mathrm{C}$ for $16 \mathrm{~h}$. Protein and lipids were stained with rhodamine B (red in a, d, g) and BODIPY 505/515 (green in b, e, h), respectively. Panels c, f, and i show merged channels of lipid and protein. White arrows indicate coalesced fat globules. Scale bars are $10 \mu \mathrm{m}$.

explained by disruption of the micellar structure during homogenization (Dalgleish et al., 2004).

The fat globules in both the blank and hydrolyzed samples were much rounder and larger than the casein micelles; the diameter of most fat globules ranged from 200 to $500 \mathrm{~nm}$, in agreement with Lopez (2005), who suggested that the volume-weighted average diameter of fat globules in homogenized milks is in the range of 200 to $500 \mathrm{~nm}$. In the blank full-fat UHT milk, as shown in Figure 8a, the surface of the fat globules appeared to be covered by wooly structures protruding from the bulk of the fat globule. These structures, with a diameter of about 10 and $20 \mathrm{~nm}$, were assumed to be casein micelle fragments, which originated from casein micelles that had been pulled apart and then spread on the fat globules during homogenization (Dalgleish et al., 2004). These wooly structures probably contained many $\kappa-\mathrm{CN}$ on their surface, because they were absent after incubation with AprX, as shown in Figure 8b. In addition, in AprX-hydrolyzed samples, fat globules appeared to be embedded in an aggregated protein network (Figure 8b). The 2 findings for the AprX-hydrolyzed samples agreed with the interpretation of both the amount of cream layer and its protein content (Figure 5a), as well as the CLSM pictures (Figure $7 \mathrm{~d}-\mathrm{f}$ ). The surface conformation of fat globules in plasmin-hydrolyzed samples (Figure 8c) was more difficult to interpret. Deduced from the FSAP hydrolysis by plasmin (Figure 6b), 
and the "protein shell" observed in the CLSM pictures (Figure $7 \mathrm{~g}-\mathrm{i}$ ), the structure covering the surface of fat globules might consist of casein micelle fragments.

\section{Comparison Between AprX- and Plasmin-Induced Fat Destabilization}

When comparing the physical and chemical changes in full-fat UHT milk samples hydrolyzed by AprX and plasmin, different mechanisms of fat destabilization can be proposed, as schematically illustrated in Figure 9. Our previous study showed that the enzyme-induced physical-chemical changes and hydrolysis of milk proteins are independent of protease concentration or temperature (Zhang et al., 2018). Therefore, the finding from the fast destabilization model systems in this study (storage at $37^{\circ} \mathrm{C}$ with the addition of high concentrations of enzymes) should also apply to lower temperatures and biological levels of the enzymes.

AprX destabilizes fat globules in full-fat UHT milk by flocculation (Figure 9). In AprX-containing samples, because AprX specifically cleaves the protruding $\kappa-\mathrm{CN}$ (Figure 5a, c), casein micelles, together with the casein micelle fragments absorbed on the surface of fat globules, quickly destabilize. Consequently, a network is formed due to reduced steric and electrostatic repulsion. Because fat globules are part of the 3-dimensional gel network, although they remain as individual entities, they are closely embedded in the continuous protein network (Figure 7d-f, Figure 8b). From the perspective of fat globules, more proteins - micellar casein aggregated with the existing FSAP - were absorbed (Figure 5). As a result, hydrodynamic diameter increased (Figure 3a), as well as viscosity (Figure 4a). Furthermore, because of the adsorption of additional milk proteins with the fat globules, increasing their density, fat globules tended to sink under gravitational force (Figure 1a).

In contrast, the mechanism responsible for the physical instability of fat globules in full-fat UHT milk induced by plasmin is fat globule partial coalescence (Figure 9). In plasmin-containing samples, plasmin preferentially hydrolyzed $\alpha$ - and $\beta$-CN (Figure $6 \mathrm{~b}, \mathrm{~d}$ ), probably causing collapse of the FSAP, which consists mainly of casein micelle fragments (Figure 8c). As a consequence, the fat globules no longer repelled each other; instead, several individual fat globules merged into a larger fat droplet (Figure 7g-i). These coalesced fat droplets led to an increase in the particle size (Figure $3 \mathrm{~b}$ ) and viscosity (Figure $4 \mathrm{~b}$ ). Because some of FSAP were cleaved by plasmin, less protein was present on the surface of the fat droplets (Figure 5), and the fat
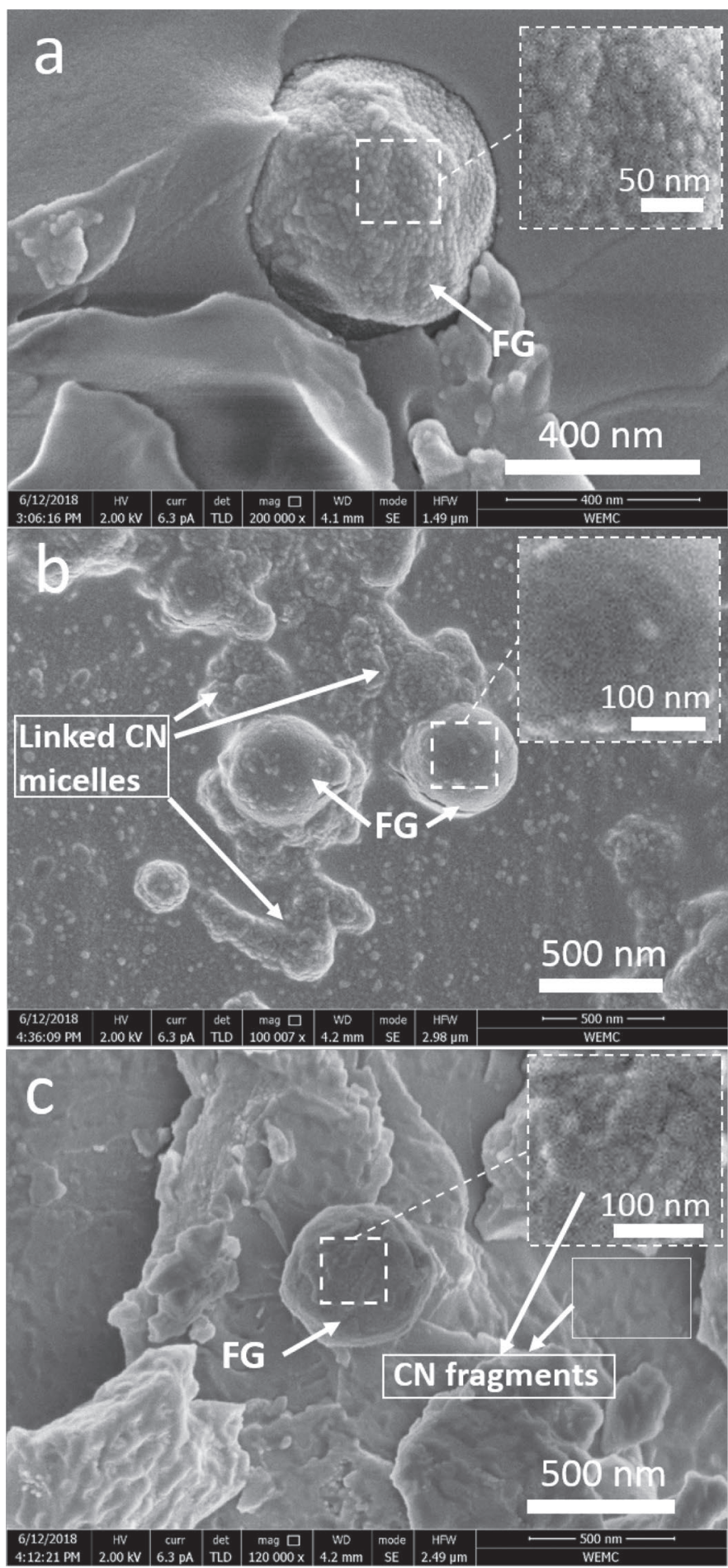

Figure 8. Cryogenic scanning electron microscopy images of fat globule(s) in (a) blank full-fat UHT milk, and full-fat UHT milk samples incubated with (b) AprX protease, or (c) plasmin at $37^{\circ} \mathrm{C}$ for 16 h. Insets show the enlargement of the fat globule surface. Scale bars are shown in the images. The linked casein micelles and casein micelle fragments discussed in the text are indicated in (b) and (c), respectively. $\mathrm{FG}=$ fat globules. 


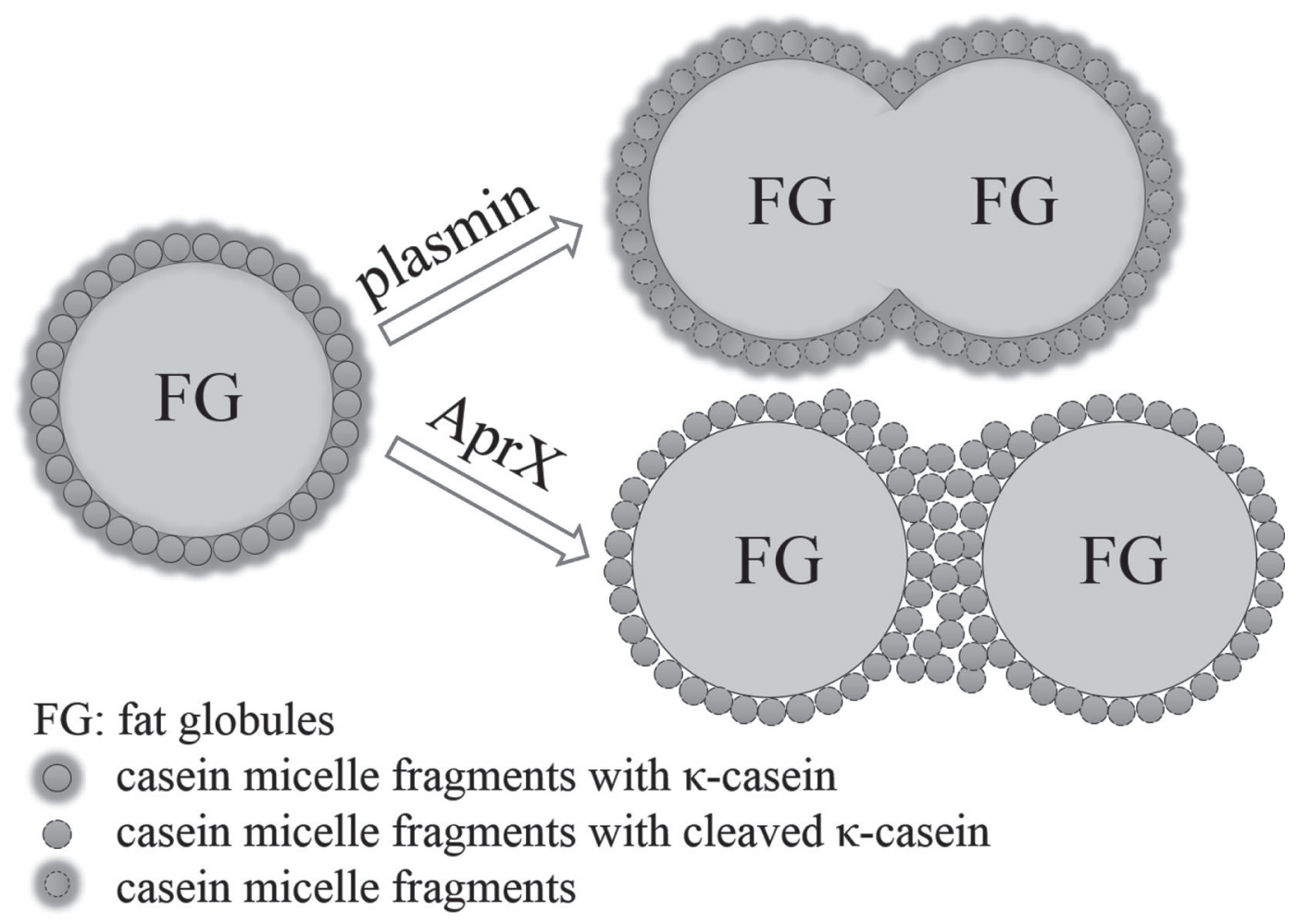

Figure 9. Simplified scheme describing the different mechanisms of fat destabilization in full-fat UHT milk induced by AprX protease and plasmin. $\mathrm{FG}=$ fat globules.

globules thus had a lower density and cream (Figure 1b). It should also be noted that a creamy layer on the top is commonly accompanied by a gel on the bottom when plasmin is present (Visser, 1981; Kohlmann et al., 1991; Stoeckel et al., 2016).

\section{CONCLUSIONS}

This study elucidated the mechanisms of fat destabilization in UHT milk as a consequence of proteolytic degradation by bacterial protease AprX and native protease plasmin. Our results showed that AprX induced sedimentation of milk fat, embedded in a protein gel network, caused by the fast hydrolysis of $\kappa-\mathrm{CN}$ leading to flocculation of casein micelles and fat globules. Plasmin, on the other hand, induced creaming in fullfat UHT milk, because the hydrolysis of $\alpha-$ and $\beta-\mathrm{CN}$ disrupted the casein micelle fragments on the milk fat globule surface, causing the fat globules to coalesce and ascend. The knowledge gained from this study can be used to determine the protease responsible for full-fat UHT milk destabilization during storage. Overall, both enzymes can bring about destabilization in full-fat UHT milk; actions should be taken to decrease the activity of both enzymes in the production chain.

\section{ACKNOWLEDGMENTS}

This research was funded by the Sino Dutch Dairy Development Center, which aims at improving dairy production, safety, and quality levels throughout the dairy chain in China (www.sdddc.org). We acknowledge Marcel Giesbers (Wageningen Electron Microscopy Centre, Wageningen, the Netherlands) for assistance in performing the Cryo-SEM experiments, and Norbert C.A. de Ruijter (Wageningen Light Microscopy Center, Wageningen, the Netherlands) for assistance in performing the CLSM experiments. The authors report no conflict of interest.

\section{REFERENCES}

Baglinière, F., A. Matéos, G. Tanguy, J. Jardin, V. Briard-Bion, F. Rousseau, B. Robert, E. Beaucher, J. L. Gaillard, C. Amiel, G. Humber, A. Dary, and F. Gaucheron. 2013. Proteolysis of ultra high temperature-treated casein micelles by AprX enzyme from Pseudomonas fluorescens $\mathrm{F}$ induces their destabilisation. Int. Dairy J. 31:55-61. https://doi.org/10.1016/j.idairyj.2013.02.011.

Baümler, E. R., G. H. Crapiste, and A. A. Carelli. 2010. Solvent extraction: Kinetic study of major and minor compounds. J. Am. Oil Chem. Soc. 87:1489-1495. https://doi.org/10.1007/s11746-010 $-1637-3$.

Cano-Ruiz, M., and R. Richter. 1997. Effect of homogenization pressure on the milk fat globule membrane proteins. J. Dairy Sci 
80:2732-2739. https://doi.org/10.3168/jds.S0022-0302(97)76235 -0 .

Chavan, R. S., S. R. Chavan, C. D. Khedkar, and A. H. Jana. 2011. UHT milk processing and effect of plasmin activity on shelf life: A review. Compr. Rev. Food Sci. Food Saf. 10:251-268. https://doi .org/10.1111/j.1541-4337.2011.00157.x.

Dalgleish, D. G., P. A. Spagnuolo, and H. D. Goff. 2004. A possible structure of the casein micelle based on high-resolution field-emission scanning electron microscopy. Int. Dairy J. 14:1025-1031. https://doi.org/10.1016/j.idairyj.2004.04.008.

Datta, N., and H. C. Deeth. 2001. Age gelation of UHT milk-A review. Food Bioprod. Process. 79:197-210. https://doi.org/10 $.1205 / 096030801753252261$.

Deeth, H., and M. Lewis. 2016. Protein stability in sterilised milk and milk products. Pages 247-286 in Advanced Dairy Chemistry. 4th ed. Vol. 1B. P. L. H. McSweeney and J. A. O'Mahony, ed. Springer, New York.

Dufour, D., M. Nicodème, C. Perrin, A. Driou, E. Brusseaux, G. Humbert, J. L. Gaillard, and A. Dary. 2008. Molecular typing of industrial strains of Pseudomonas spp. isolated from milk and genetical and biochemical characterization of an extracellular protease produced by one of them. Int. J. Food Microbiol. 125:188-196. https: //doi.org/10.1016/j.ijfoodmicro.2008.04.004.

Hardham, J. F. 1998. Effect of protein standardisation of milk by addition of UF milk permeate on the composition and storage stability of UHT processed milk. Aust. J. Dairy Technol. 53:22-27.

Hardham, J. F., B. W. Imison, and H. M. French. 2000. Effect of homogenisation and microfluidisation on the extent of fat separation during storage of UHT milk. Aust. J. Dairy Technol. 55:16-22.

Harwalkar, V. R. 1992. Age gelation of sterilized milks. Pages 691-734 in Advanced Dairy Chemistry. 2nd ed. Vol. 1. P. F. Fox, ed. Elsevier, London, UK.

Jenness, R. R., and J. Koops. 1962. Preparation and properties of a salt solution which simulates milk ultrafiltrate. Neth. Milk Dairy J. 16:153-164.

Kamigaki, T., Y. Ito, Y. Nishino, and A. Miyazawa. 2018. Microstructural observation of casein micelles in milk by cryo-electron microscopy of vitreous sections (CEMOVIS). Microscopy (Oxf.) 67:164-170. https://doi.org/10.1093/jmicro/dfy012.

Kohlmann, K. L., S. S. Nielsen, and M. R. Ladisch. 1991. Effects of a low concentration of added plasmin on ultra-high temperature processed milk. J. Dairy Sci. 74:1151-1156. https://doi.org/10.3168/ jds.S0022-0302(91)78267-2.

Lopez, C. 2005. Focus on the supramolecular structure of milk fat in dairy products. Reprod. Nutr. Dev. 45:497-511. https://doi.org/ 10.1051/rnd:2005034.

Lu, J., N. Argov-Argaman, J. Anggrek, S. Boeren, T. van Hooijdonk, J. Vervoort, and K. A. Hettinga. 2016. The protein and lipid composition of the membrane of milk fat globules depends on their size. J. Dairy Sci. 99:4726-4738. https://doi.org/10.3168/jds.2015 -10375 .

Lu, J., J. Pickova, J. L. Vázquez-Gutiérrez, and M. Langton. 2018. Influence of seasonal variation and ultra high temperature processing on lipid profile and fat globule structure of Swedish cow milk. Food Chem. 239:848-857. https://doi.org/10.1016/j.foodchem 2017.07.018.

Malmgren, B., Y. Ardö, M. Langton, A. Altskär, M. G. Bremer, P. Dejmek, and M. Paulsson. 2017. Changes in proteins, physical stability and structure in directly heated UHT milk during storage at different temperatures. Int. Dairy J. 71:60-75. https://doi.org/10 .1016/j.idairyj.2017.03.002.

Matéos, A., M. Guyard-Nicodème, F. Baglinière, J. Jardin, F. Gaucheron, A. Dary, G. Humbert, and J. L. Gaillard. 2015. Proteolysis of milk proteins by AprX, an extracellular protease identified in Pseudomonas LBSA1 isolated from bulk raw milk, and implications for the stability of UHT milk. Int. Dairy J. 49:78-88. https:/ /doi.org/10.1016/j.idairyj.2015.04.008.

McCrae, C. H., D. Hirst, A. J. R. Law, and D. D. Muir. 1994. Heatstability of homogenized milk - role of interfacial protein. J. Dairy Res. 61:507-516. https://doi.org/10.1017/S0022029900028430.
McPherson, A. V., M. C. Dash, and B. J. Kitchen. 1984. Isolation and composition of milk fat globule membrane material: II. From homogenized and ultra heat treated milks. J. Dairy Res. 51:289-297. https://doi.org/10.1017/S0022029900023554.

Ong, L., R. R. Dagastine, S. E. Kentish, and S. L. Gras. 2011. Microstructure of milk gel and cheese curd observed using cryo scanning electron microscopy and confocal microscopy. Lebensm. Wiss. Technol. 44:1291-1302. https://doi.org/10.1016/j.lwt.2010.12.026.

Petrella, G., S. Pati, R. Gagliardi, A. Rizzuti, P. Mastrorilli, B. La Gatta, and A. Di Luccia. 2015. Study of proteolysis in river buffalo mozzarella cheese using a proteomics approach. J. Dairy Sci. 98:7560-7572. https://doi.org/10.3168/jds.2015-9732.

Ramsey, J. A., and K. R. Swartzel. 1984. Effect of ultra high temperature processing and storage conditions on rates of sedimentation and fat separation of aseptically packaged milk. J. Food Sci. 49:257-262. https://doi.org/10.1111/j.1365-2621.1984.tb13721.x.

Rauh, V. M., L. B. Johansen, R. Ipsen, M. Paulsson, L. B. Larsen, and M. Hammershøj. 2014a. Plasmin activity in UHT milk: Relationship between proteolysis, age gelation, and bitterness. J. Agric. Food Chem. 62:6852-6860. https://doi.org/10.1021/if502088u.

Rauh, V. M., A. Sundgren, M. Bakman, R. Ipsen, M. Paulsson, L. B. Larsen, and M. Hammershøj. 2014b. Plasmin activity as a possible cause for age gelation in UHT milk produced by direct steam infusion. Int. Dairy J. 38:199-207. https://doi.org/10.1016/j.idairyj .2013.12.007.

Recio, I., M. R. García-risco, M. Ramos, and R. López-fandiño. 2000. Characterization of peptides produced by the action of psychrotrophic proteinases on K-casein. J. Dairy Res. 67:625-630. https://doi .org/10.1017/s002202990000443x.

Stoeckel, M., M. Lidolt, V. Achberger, C. Glück, M. Krewinkel, T. Stressler, M. von Neubeck, M. Wenning, S. Scherer, and J. Hinrichs. 2016. Growth of Pseudomonas weihenstephanensis, Pseudomonas proteolytica and Pseudomonas sp. in raw milk: Impact of residual heat-stable enzyme activity on stability of UHT milk during shelf-life. Int. Dairy J. 59:20-28. https://doi.org/10.1016/j .idairyj.2016.02.045.

Sunds, A. V. 2016. Evaluation of accelerated shelf life testing of UHT milk. MS Thesis. Department of Food Science, Aarhus University, Aarhus, Denmark

Torres, I. C., J. M. A. Rubio, and R. Ipsen. 2012. Using fractal image analysis to characterize microstructure of low-fat stirred yoghurt manufactured with microparticulated whey protein. J. Food Eng. 109:721-729. https://doi.org/10.1016/j.jfoodeng.2011.11.016.

Visser, S. 1981. Proteoloytic enzymes and their action on milk proteins. A review. Neth. Milk Dairy J. 35:65-88.

Wilbey, R. A. 2011. Homogenization of milk: Principles and mechanism of homogenization, effects and assessment of efficiency: Valve homogenizers. Pages 750-754 in Encyclopedia of Dairy Sciences. 2nd ed. J. W. Fuquay, ed. Academic Press, San Diego, CA.

Zhang, C., E. Bijl, and K. Hettinga. 2018. Destabilization of UHT milk by protease AprX from Pseudomonas fluorescens and plasmin. Food Chem. 263:127-134. https://doi.org/10.1016/j.foodchem .2018.04.128.

Zhang, C., E. Bijl, B. Svensson, and K. Hettinga. 2019. The extracellular protease AprX from Pseudomonas and its spoilage potential for UHT milk: A review. Compr. Rev. Food Sci. Food Saf. 18:834-852. https://doi.org/10.1111/1541-4337.12452.

\section{ORCIDS}

Chunyue Zhang (ํ) https://orcid.org/0000-0002-9706-8129

Etske Bijl $\odot$ https://orcid.org/0000-0002-7363-5387

Karinska Eunike Muis @ https://orcid.org/0000-0003-4090-0997

Kasper Hettinga @i) https://orcid.org/0000-0002-9017-4447 